\title{
Serum Levels of Interleukin-8 and Soluble Interleukin-6 Receptor in Patients with Stage-I Multiple Myeloma: A Case-Control Study
}

\author{
Maryam Kohsari, Mohammad-Hassan Khadem-Ansari*, Yousef Rasmi, Hojjat \\ Sayyadi
}

\begin{abstract}
Objective: Multiple myeloma (MM) remains an incurable disease that needs better recognition and further research. Previous studies elucidated the interaction between myeloma cells and showed the necessity of bone marrow stromal cells for the initiation and progression of MM. Many chemokines and their receptors including interleukin-8 (IL-8) and soluble interleukin-6 receptor (sIL-6R) play important roles in this interaction. The main purpose of this study is evaluating the serum level of IL-8 and sIL-6R on stage-I of MM patients and healthy controls. Methods: Serum samples from 30 stage-I MM patients (13 males and 17 females) and 30 healthy subjects as controls (13 males and 17 females) were examined in this study. The protein concentrations of serum IL- 8 and sIL-6R were assessed by enzyme-linked immunosorbent assay (ELISA). Results: The mean level of IL-8 and sIL-6R were significantly elevated in stage-I MM. The mean levels of IL-8 were $1246.57 \pm 279.22 \mathrm{ng} / \mathrm{ml}$ in stage-I MM and $902.53 \pm 294.61 \mathrm{ng} / \mathrm{ml}$ in controls $(\mathrm{P}<0.001)$. The mean levels of sIL-6R were $5.39 \pm 1.38 \mathrm{ng} / \mathrm{ml}$ and $4.1 \pm 1.14 \mathrm{ng} / \mathrm{ml}$ in stage-I MM and controls, respectively $(\mathrm{P}<0.001)$. The mean levels of IL-8 were $1342.18 \pm 193.4 \mathrm{ng} / \mathrm{ml}$ in patient females and $859 \pm 278.2 \mathrm{ng} /$ $\mathrm{ml}$ in control females $(\mathrm{P}<0.001)$. The mean levels of sIL-6R were $5.21 \pm 1.55 \mathrm{ng} / \mathrm{ml}$ and $3.91 \pm 1.22 \mathrm{ng} / \mathrm{ml}$ in patient females and control females, respectively $(\mathrm{P}=0.01)$. The mean level of sIL-6R in patient males and control males were $5.63 \pm 1.43 \mathrm{ng} / \mathrm{ml}$ and $4.34 \pm 1.04 \mathrm{ng} / \mathrm{ml}$, respectively $(\mathrm{P}=0.01)$. A significant correlation (Pearson's correlation $=0.45$, $\mathrm{P}=0.008$ ) was observed in the population of females (patients and controls). Conclusion: The results of study suggest the possible involvement of IL-8 and the sIL-6R at stage-I MM and can better characterize the role of chemokines and their receptors in the disease process, especially in the early stages.
\end{abstract}

Keywords: Multiple myeloma- interleukin-8- soluble interleukin-6 receptor

Asian Pac J Cancer Prev, 21 (1), 127-132

\section{Introduction}

Multiple myeloma (MM) accounts for almost $1 \%$ of all cancers and $10 \%$ of hematological malignancy (Alexanian and Dimopoulos, 1994; Kastritis et al., 2009). This disease still remains incurable (Bustoros et al., 2017) and is characterized by increasing monoclonal immunoglobulin secreted by clonal malignant plasma cells within the bone marrow (BM) and the clinical evidence such as osteolytic bone lesions, hypercalcemia, renal disease, and anemia (Coleman, 1997; Mahindra et al., 2010). The interaction between myeloma cells and bone marrow stromal cells (BMSCs) is crucial to homing, proliferation, migration, and drug-resistant (Aggarwal et al., 2006). Clearly, myeloma cells and BMSCs both express a variety of chemokine receptors. Moreover, they produce various chemokines by the interaction of chemokine receptors and their ligands in BM- microenvironment, which promotes the progression of MM (Wallace et al., 2001).

Interleukin-8 (IL-8) belongs to the alpha chemokine family of cytokines (Yoshimura et al., 1987) and has a chemotactic effect on neutrophils, eosinophils, basophils, monocytes, and B lymphocytes (Strieter, 2002). The overexpression in a variety of tumors has led to investigating its role in tumor progression (Green et al., 1997). In this regard, several studies have illustrated the role of IL-8 in angiogenesis, cell motility, and invasion in tumor metastasis (Sozzani et al., 1996; Belperio et al., 2000; Mukaida, 2000). Interleukin-8 is secreted by endothelial cells and BMSCs in MM (Merico et al., 1993; Pellegrino et al., 2005). It is hypothesized that IL-8 attracts malignant plasma cell precursors that are in the blood into an interleukin-6 rich bone marrow microenvironment (Lauta, 2003). In addition, IL-8 stimulates osteoblast 
proliferation and bone resorption by regulating receptor activator of nuclear factor kappa-B ligand (Bendre et al., 2003).

Interleukin-6 is the main growth and survival factor of myeloma cells and is over-produced in the form of paracrine by BMSCs in contact with myeloma cells (Anderson and Carrasco, 2011). Interleukin-6 induces its effect through its specific receptor at the target cell surface (Taga and Kishimoto, 1997). Soluble interleukin-6 receptor (sIL-6R) is the alternatively spliced cleaved form of interleukin- 6 receptor that lacks the transmembrane domain but is able to mediate the effect of IL- 6 through the trance-signaling pathway (Rose-John and Heinrich, 1994; Jones et al., 2011). In this context, it has been reported that there is a connection between elevated levels of sIL-6R and poor prognosis and shorter survival in MM patients (Kyrtsonis et al., 1996; Stasi et al., 1998). In this study, we postulated that IL- 8 and sIL-6R may be elevated in stage-I of MM patients and contribute to the progression of the disease. To explore this issue, we performed a case-control study to assess the serum level of IL-8 and sIL-6R in stage-I of MM patients and healthy controls.

\section{Materials and Methods}

\section{Patient and control}

The study population includes 30 diagnosed stage-I MM patients (13 males and 17 females; with mean age $64.9 \pm 7.2$ years) and 30 healthy controls (13 males and 17 females; with a mean age of $64.6 \pm 6.5$ years) used as controls.

\section{To confirm patients are stage-I MM, several experiments were performed}

Laboratory tests including the complete blood count $(\mathrm{CBC})$ for examining the anemia, erythrocyte sedimentation rate (ESR) that must be in patient more than $80 \mathrm{~mm} /$ hour, blood chemistry tests for evaluated serum level of creatinine to check kidney function, albumin, calcium, and lactic dehydrogenase (LDH) (Pars Azmun, Tehran, Iran) were used to measure all factors of blood chemistry. Next, $\beta 2$-microglobulin (LIAISON ${ }^{\circ}$, DiaSorin, Italy) was measured and serum capillary zone electrophoresis (Capillary ${ }^{\circledR}$, Sebia, France) was performed to see the peak in the gamma area. Moreover, immunotyping was carried out to detect the type of light chains (kappa or lambda). The bone marrow tissue biopsy was taken from the patients to examine the size and shape of the cells and see how the cells are arranged. The criteria to diagnose MM is observing at least $10 \%$ of plasma cells in the bone marrow biopsy.

In the end, the results of the experiments were evaluated with the International Staging System (ISS) (Greipp et al., 2005) and the stage of the disease was determined. Patients with advanced stages were excluded from the study. Also, none of the patients had received chemotherapy or radiotherapy prior to sampling. Healthy controls were examined for the absence of inflammatory diseases and other underlying conditions that could affect the outcome of the study. Eventually, the samples that confirmed the lack of evidence of impairment entered the study.

\section{Blood sampling}

Blood samples were obtained through overnight fasting. The serum was separated via centrifuge at $300 \mathrm{~g}$ for $10 \mathrm{~min}$. Then, it was transferred to the cryotubes and stored at $-70^{\circ} \mathrm{C}$ and assayed at the end of the study, to avoid inter-assay variability.

\section{Measurement of IL-8 and SIL-6R}

The serum level of IL- 8 was measured by a quantitative sandwich enzyme immunoassay method using Bioassay Technology Laboratory (Shanghai Crystal Day Biotech Co., Ltd). Briefly, a monoclonal antibody specific for IL-8 was pre-coated onto a microplate. Standard and samples were pipetted into the cells. After washing, an enzyme-linked monoclonal antibody specific for IL-8 was added into the wells. Upon adding a substrate solution, the intensity of the color, which develops in each well in proportion to the amount of IL-8 bound during the initial step, is measured by performed ELISA reader at $450 \mathrm{~nm}$ and $630 \mathrm{~nm}$ wavelength. In the same way and according to manufacturer instruction, serum level of sIL-6R was measured in accordance with the instructions given in (Shanghai Crystal Day Biotech Co., Ltd).

\section{Statistical methods}

Data analysis was performed by SPSS software (SPSS Inc. Released 2007. SPSS for Windows, Version 16.0. Chicago, USA). All measured parameters are expressed as mean $\pm \mathrm{SD}$. Before the analysis, the data were checked for normality with the Kolmogorov-Smirnov test. The parametric Independent-Samples T-test was used to perform statistical comparisons between the stage-I of MM patients and controls. Correlation between the measured parameters was calculated by Pearson's correlation. P-values $<0.05$ were considered as statistically significant.

\section{Results}

Demographic features and clinical characteristics of patients and healthy controls are reported in Table 1 . The mean serum level of IL- 8 in stage-I MM patients was $1246.57 \pm 279.22 \mathrm{ng} / \mathrm{ml}$, although it was higher than the mean of controls, which is $902.53 \pm 294.61 \mathrm{ng} / \mathrm{ml}$ $(\mathrm{P}<0.001)$ (Figure 1). A similar result was observed for

Table 1. Demographic Features and Clinical Characteristics of MM and Controls

\begin{tabular}{lccc}
\hline & MM & Controls & P-value \\
\hline Age (year) & $64.9 \pm 7.2$ & $64.6 \pm 6.5$ & 0.83 \\
Gender (male/female) & $13 / 17$ & $13 / 17$ & 1.00 \\
Hemoglobin (g/dl) & $12.62 \pm 0.89$ & $13.10 \pm 1.2$ & 0.82 \\
ESR (mm/hour) & $86.53 \pm 5.14$ & $19.73 \pm 13.26$ & $<0.001$ \\
Calcium (mg/dl) & $9.03 \pm 0.88$ & $8.80 \pm 0.84$ & 0.30 \\
Creatinine (mg/dl) & $0.98 \pm 0.18$ & $0.86 \pm 0.17$ & 0.01 \\
LDH (u/l) & $176.36 \pm 31.19$ & $165.83 \pm 26.87$ & 0.16 \\
Albumin (g/dl) & $3.91 \pm 0.52$ & $5.02 \pm 0.35$ & $<0.001$ \\
$\beta_{2}$-microglobulin (mg/dl) & $1.72 \pm 0.66$ & $1.58 \pm 0.49$ & 0.35 \\
\hline
\end{tabular}



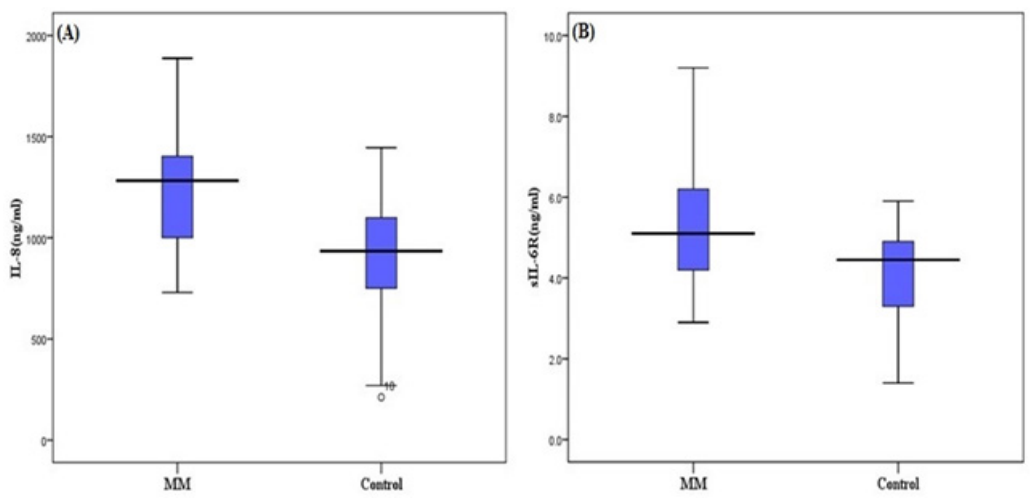

Figure 1. Distribution of Serum Level of IL-8 (A) and sIL-6R (B) between MM (multiple myeloma patients) and Controls. A significant difference is observed $(\mathrm{P}<0.001)$.
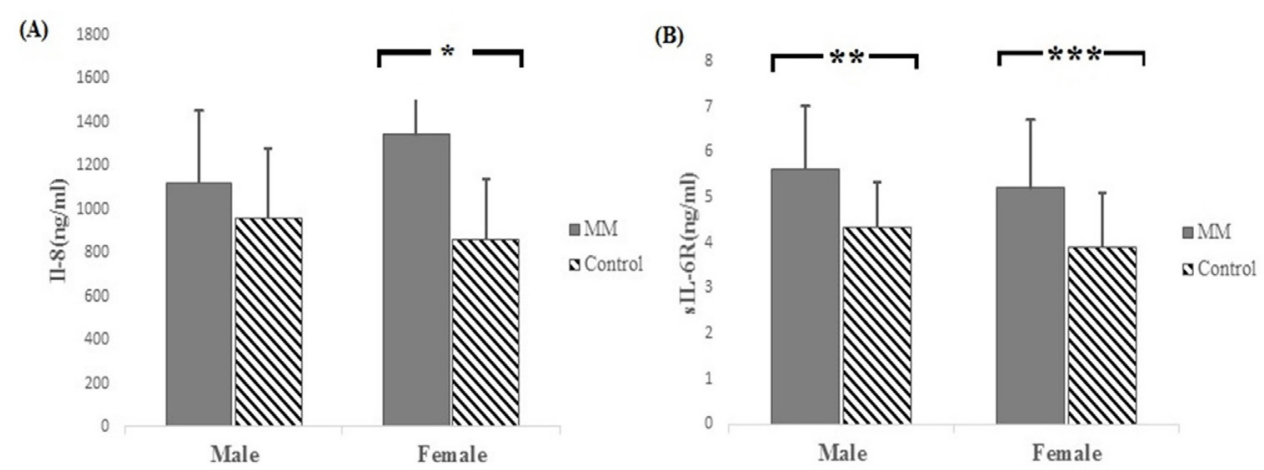

Figure 2. Comparison of the Mean Level of IL-8 (A) and sIL-6R (B) in the Population of Males and Females. Results show a significant difference in the mean level of IL-8 in females $\left({ }^{*} \mathrm{P}<0.001\right)$. The mean level of sIL-6R is significantly different in both males $(* * \mathrm{P}=0.01)$ and females $(* * * \mathrm{P}=0.01)$.

sIL-6R such that the mean serum levels of sIL-6R in patients and controls were $5.39 \pm 1.38 \mathrm{ng} / \mathrm{ml}$ and $4.1 \pm 1.14$ ng/ml, respectively $(\mathrm{P}<0.001)$ (Figure 1$)$.

There was also a significant difference between the mean level of IL-8 and sIL-6R among patient females and control females. The mean IL-8 in patient females was $1342.18 \pm 193.4 \mathrm{ng} / \mathrm{ml}$ while in the control females, it was $859 \pm 278.2 \mathrm{ng} / \mathrm{ml}(\mathrm{P}<0.001)$. Moreover, the mean sIL-6R in patient females and control females was $5.21 \pm 1.55 \mathrm{ng} / \mathrm{ml}$ and $3.91 \pm 1.22 \mathrm{ng} / \mathrm{ml}$, respectively $(\mathrm{P}=0.01)$. In the population of males, a significant difference was observed in the mean serum level of sIL-6R between patient males $(5.63 \pm 1.43 \mathrm{ng} / \mathrm{ml})$ and control males $(4.34 \pm 1.04 \mathrm{ng} / \mathrm{ml})(\mathrm{P}=0.01)$ (Figure 2).
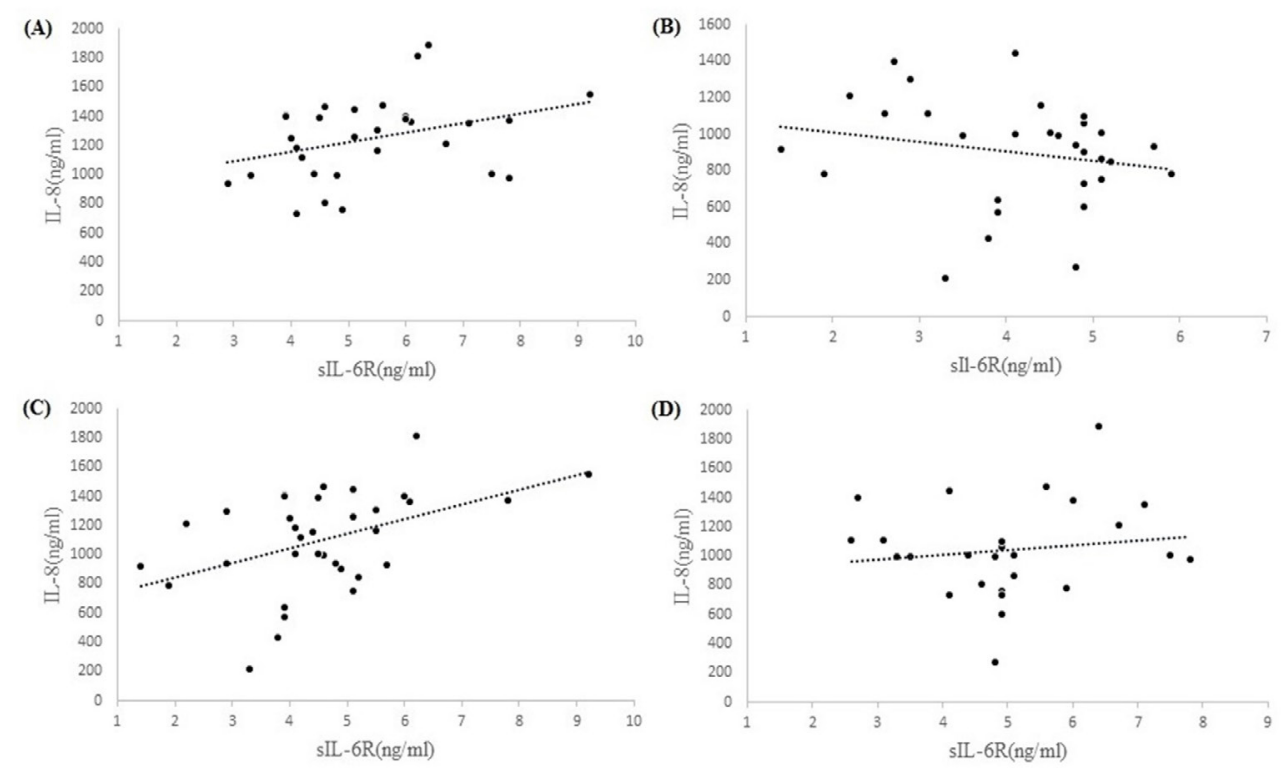

Figure 3. Correlation between IL-8 and sIL-6R in MM (A), Controls (B), Population of Females (C) and Population of Males (D). The results show significant correlation in population of females (Pearson's correlation $=0.45, \mathrm{P}=0.008$ ). Correlations are in patients (Pearson's correlation $=0.34, \mathrm{p}=0.06$ ), controls (Pearson's correlation $=-0.20, \mathrm{P}=0.28$ ), and population of males (Pearson's correlation $=0.13, \mathrm{P}=0.51$ ). 
The results showed no significant correlation between IL-8 and sIL-6R with any of the measured parameters and also no significant correlation between IL-8 and sIL-6R in patients (Pearson's correlation $=0.34, \mathrm{P}=0.06$ ), controls (Pearson's correlation $=-0.20, \mathrm{P}=0.28$ ), and males population (Pearson's correlation $=0.13, \mathrm{P}=0.51$ ). Only a significant correlation was observed between IL-8 and sIL-6R in the population of females (Pearson's correlation $=0.45, \mathrm{P}=0.008)$ (Figure 3 ).

\section{Discussion}

Multiple myeloma is a cancer of plasma cells resulting from the abnormal proliferation of malignant plasma cells within the BM microenvironment (Coleman, 1997). Despite the advancement in the detection and emergence of new treatments, this disease remains still incurable (Bustoros et al., 2017). The exact cause of the disease has not been known until now (Angtuaco et al., 2004). However, a deeper understanding of the molecular mechanisms of MM growth, survival, and resistance to therapy, as well as the interaction between MM cell and BM microenvironment will provide the framework for the development of novel therapies to further improve the outcome of patients. In our previous studies, we focused on the role of stress oxidative in Stage-I MM and show that oxidative stress are considered in the primary pathogenesis of MM diseases (Faridvand et al., 2016; Khadem-Ansari et al., 2017). To the best of authors' knowledge, there is no study on serum level of IL-8 and sIL-6R, especially on stage-I MM. In this study, our goal was to investigate the changes in serum level of Interleukin-8 and sIL-6R in stage-I MM patients. IL-8 promotes cancer cell growth, survival, angiogenesis, and metastasis in several tumors (Arenberg et al., 1996; Luca et al., 1997; Singh and Varney, 2000; Kim et al., 2001). In MM, endothelial cells and BMSCs produce overexpression of IL-8 (Merico et al., 1993; Pellegrino et al., 2005). According to a hypothesis, IL-8 may play a role to attract circulating malignant plasma cell precursors existing in the blood into an IL-6-rich bone marrow microenvironment (Lauta, 2003). Our results show that increased serum levels of IL8 in patients compared to healthy controls. In one study, Herrero et al., (2016) showed the effects of IL-8 up-regulation on osteoclast genesis in MM. The results are also proven in the breast cancer cell line (Gür et al., 2002; Kristo et al., 2002; Martin, 2002). Other previous studies have revealed the similar role of interleukin-8 in other cancer cell lines. IL8 correlates with angiogenesis in gastric carcinoma (Kitadai et al., 1999) and colon cancer (Fidler, 1997). IL-8 has also been shown to be an autocrine growth factor for melanoma cell and human liver and pancreatic cancer (Miyamoto et al., 1998). The role of IL-8 in metastasis has also been identified in melanoma cancer (Singh et al., 1994), gastric carcinoma (Kitadai et al., 2000), ovarian cancer (Xu and Fidler, 2000), and prostate cancer (Greene et al., 1997). Our data demonstrate an increased level of sIL-6R in patients compared with a healthy control group. Studies on sIL-6R in MM represent the role of this factor in bone resorption by stimulating osteoclast formation (Tamura et al., 1993). Moreover, it was reported that the circulating levels of sIL-6R can act as a useful prognosis marker since high serum sIL-6R concentrations were associated with patients who died within 3 years of diagnosis (Pulkki et al., 1996). Although we found a correlation between IL-8 and sIL6R only among the population of females, these two factors have similar roles in bone destruction as the most important complications and causes of the disease (Mundy et al., 1974; Walker et al., 2007). It has been show that sIL-6R is involved in inducing interleukin-6 activity (Taga and Kishimoto, 1997). In this regard, there is clear evidence to support that both autocrine and paracrine mechanisms of IL- 6 and IL-8 production have a correlation with the promotion of MM cell growth, survival, and migration, and angiogenesis in the BM- microenvironment (Zhu et al., 2003; Ndlovu et al., 2009). Considering the existing evidence and in order to clarify the process of MM disease, however, further research is needed on these two factors.

In conclusion, the results of the study suggest that IL-8 and sIL-6R are involved in the development of MM in stage-I. Regarding the need for better understanding of the disease, especially in the first stage, the results demonstrate the role of chemokines and their receptors in the disease process in stage I of MM. Furthermore, this two factors can be used for choice better therapeutic strategies.

\section{Acknowledgments}

This work derived from a Master of Science thesis in biochemistry and we thank the Urmia University of Medical Sciences (department of biochemistry) for kindly providing and supporting this project.

\section{Funding Statement}

This research did not receive any fund or financial support.

\section{Statement Conflict of Interest}

We declare that we have no conflict of interest.

\section{References}

Aggarwal R, Ghobrial IM, Roodman GD (2006). Chemokines in multiple myeloma. Exp Hematol, 34, 1289-95.

Alexanian R, Dimopoulos M (1994). The treatment of multiple myeloma. $N$ Engl J Med, 330, 484-9.

Anderson KC, Carrasco RD (2011). Pathogenesis of myeloma. Annu Rev Pathol, 6, 249-74.

Angtuaco EJ, Fassas AB, Walker R, et al (2004). Multiple myeloma: clinical review and diagnostic imaging. Radiology, 231, 11-23.

Arenberg DA, Kunkel SL, Polverini PJ, et al (1996). Inhibition of interleukin- 8 reduces tumorigenesis of human non-small cell lung cancer in SCID mice. J Clin Invest, 97, 2792-802.

Belperio JA, Keane MP, Arenberg DA, et al (2000). CXC chemokines in angiogenesis. $J$ Leukoc Biol, 68, 1-8.

Bendre MS, Montague DC, Peery T, et al (2003). Interleukin-8 stimulation of osteoclastogenesis and bone resorption is a mechanism for the increased osteolysis of metastatic bone disease. Bone, 33, 28-37. 
Bustoros M, Mouhieddine TH, Detappe A, et al (2017). Established and novel prognostic biomarkers in multiple myeloma. Am Soc Clin Oncol Educ Book, 37, 548-60.

Coleman RE (1997). Skeletal complications of malignancy. Cancer, 80, 1588-94.

Faridvand Y, Oskuyi AE, Khadem-Ansari MH (2016). Serum 8 -isoprostane levels and paraoxonase 1 activity in patients with stage I multiple myeloma. Redox Rep, 21, 204-8.

Fidler IJ (1997). Critical determinants of human colon cancer metastasis. In 'Molecular pathology of gastroenterological cancer', Eds Springer, pp 147-69.

Green AR, Green VL, White MC, et al (1997). Expression of cytokine messenger RNA in normal and neoplastic human breast tissue: Identification of interleukin- 8 as a potential regulatory factor in breast tumours. Int J Cancer, 72, 937-41.

Greene GF, Kitadai Y, Pettaway CA, et al (1997). Correlation of metastasis-related gene expression with metastatic potential in human prostate carcinoma cells implanted in nude mice using an in situ messenger RNA hybridization technique. Am J Pathol, 150, 1571.

Greipp PR, Miguel JS, Durie BG, et al (2005). International staging system for multiple myeloma. J Clin Oncol, 23, 3412-20.

Gür A, Denli A, Nas K, et al (2002). Possible pathogenetic role of new cytokines in postmenopausal osteoporosis and changes during calcitonin plus calcium therapy. Rheumatol Int, 22, 194-8.

Herrero AB, García-Gómez A, Garayoa M, et al (2016). Effects of IL-8 up-regulation on cell survival and osteoclastogenesis in multiple myeloma. Am J Pathol, 186, 2171-82.

Jones SA, Scheller J, Rose-John S (2011). Therapeutic strategies for the clinical blockade of IL-6/gp130 signaling. J Clin Invest, 121, 3375-83.

Kastritis E, Palumbo A, Dimopoulos MA (2009). Treatment of relapsed/refractory multiple myeloma. Semin Hematol, 46, 143-57.

Khadem-Ansari M, Nozari S, Asoudeh M, et al (2017). Elevated serum 8-Hydroxy-2'-Deoxyguanosine, Nitrite, and Nitrate in patients with stage I Multiple Myeloma. Int J Cancer Manag, 10, e8493.

Kim SJ, Uehara H, Karashima T, et al (2001). Expression of interleukin-8 correlates with angiogenesis, tumorigenicity, and metastasis of human prostate cancer cells implanted orthotopically in nude mice. Neoplasia, 3, 33-42.

Kitadai Y, Haruma K, Mukaida N, et al (2000). Regulation of disease-progression genes in human gastric carcinoma cells by interleukin 8. Clin Cancer Res, 6, 2735-40.

Kitadai Y, Takahashi Y, Haruma K, et al (1999). Transfection of interleukin-8 increases angiogenesis and tumorigenesis of human gastric carcinoma cells in nude mice. Br J Cancer, 81, 647.

Kristo C, Godang K, Ueland T, et al (2002). Raised serum levels of interleukin- 8 and interleukin-18 in relation to bone metabolism in endogenous Cushing's syndrome. Eur $J$ Endocrinol, 146, 389-95.

Kyrtsonis MC, Dedoussis G, Zervas C, et al (1996). Soluble interleukin-6 receptor (sIL-6R), a new prognostic factor in multiple myeloma. Br J Haematol, 93, 398-400.

Lauta VM (2003). A review of the cytokine network in multiple myeloma: diagnostic, prognostic, and therapeutic implications. Cancer, 97, 2440-52.

Luca M, Huang S, Gershenwald JE, et al (1997). Expression of interleukin- 8 by human melanoma cells up-regulates MMP-2 activity and increases tumor growth and metastasis. $\mathrm{Am} \mathrm{J}$ Pathol, 151, 1105.

Mahindra A, Hideshima T, Anderson KC (2010). Multiple myeloma: biology of the disease. Blood Rev, 24, 5-11.
Martin TJ (2002). Manipulating the environment of cancer cells in bone: a novel therapeutic approach. $J$ Clin Invest, 110, 1399-401.

Merico F, Bergui L, Gregoretti M, et al (1993). Cytokines involved in the progression of multiple myeloma. Clin Pharmacokinet, 92, 27-31.

Miyamoto M, Shimizu Y, Okada K, et al (1998). Effect of interleukin- 8 on production of tumor-associated substances and autocrine growth of human liver and pancreatic cancer cells. Cancer Immunol Immunother, 47, 47-57.

Mukaida N (2000). Interleukin-8: an expanding universe beyond neutrophil chemotaxis and activation. Int $J$ Hematol, 72, 391-8.

Mundy GR, Raisz LG, Cooper RA, et al (1974). Evidence for the secretion of an osteoclast stimulating factor in myeloma. N Engl J Med, 291, 1041-6.

Ndlovu MN, Van Lint C, Van Wesemael K, et al (2009). Hyperactivated NF- $\kappa \mathrm{B}$ and AP-1 transcription factors promote highly accessible chromatin and constitutive transcription across the interleukin- 6 gene promoter in metastatic breast cancer cells. Mol Cell Biol, 29, 5488-504.

Pellegrino A, Ria R, Pietro GD, et al (2005). Bone marrow endothelial cells in multiple myeloma secrete CXC-chemokines that mediate interactions with plasma cells. Br J Haematol, 129, 248-56.

Pulkki K, Pelliniemi TT, Rajamäki A, et al (1996). Soluble interleukin-6 receptor as a prognostic factor in multiple myeloma. Br J Haematol, 92, 370-4.

Rose-John S, Heinrich PC (1994). Soluble receptors for cytokines and growth factors: generation and biological function. Biochem J, 300, 281.

Singh R, Varney M (2000). Invited Reviews-IL-8 expression in malignant melanoma: Implications in growth and metastasis. Histol Histopathol, 15, 843-50.

Singh RK, Gutman M, Radinsky R, et al (1994). Expression of interleukin 8 correlates with the metastatic potential of human melanoma cells in nude mice. Cancer Res, 54, 3242-7.

Sozzani S, Locati M, Allavena P, et al (1996). Chemokines: a superfamily of chemotactic cytokines. Int J Clin Lab Res, 26, 69-82.

Stasi R, Brunetti M, Parma A, et al (1998). The prognostic value of soluble interleukin-6 receptor in patients with multiple myeloma. Cancer, 82, 1860-6.

Strieter RM (2002). Interleukin-8: a very important chemokine of the human airway epithelium. Am J Physiol Lung Cell Mol Physiol, 283, 688-9.

Taga T, Kishimoto T (1997). Gp130 and the interleukin-6 family of cytokines. Annu Rev Immunol, 15, 797-819.

Tamura T, Udagawa N, Takahashi N, et al (1993). Soluble interleukin-6 receptor triggers osteoclast formation by interleukin 6. Proc Natl Acad Sci U S A, 90, 11924-8.

Walker R, Barlogie B, Haessler J, et al (2007). Magnetic resonance imaging in multiple myeloma: diagnostic and clinical implications. J Clin Oncol, 25, 1121-8.

Wallace SR, Oken MM, Lunetta KL, et al (2001). Abnormalities of bone marrow mesenchymal cells in multiple myeloma patients. Cancer, 91, 1219-30.

$\mathrm{Xu} \mathrm{L}$, Fidler IJ (2000). Acidic pH-induced elevation in interleukin 8 expression by human ovarian carcinoma cells. Cancer Res, 60, 4610-6.

Yoshimura T, Matsushima K, Tanaka S, et al (1987). Purification of a human monocyte-derived neutrophil chemotactic factor that has peptide sequence similarity to other host defense cytokines. Proc Natl Acad Sci U S A, 84, 9233-7.

Zhu YM, Bradbury DA, Pang L, et al (2003). Transcriptional regulation of interleukin (IL)-8 by bradykinin in human 
Maryam Kohsari et al

airway smooth muscle cells involves prostanoid-dependent activation of AP-1 and nuclear factor (NF)-IL-6 and prostanoid-independent activation of NF- $\mathrm{kB}$. J Biol Chem, 278, 29366-75.

\section{๑๐ब}

This work is licensed under a Creative Commons AttributionNon Commercial 4.0 International License. 